\title{
The P2X7 Receptor Contributes to the Development of the Exacerbated Inflammatory Response Associated with Sepsis
}

\author{
Patricia Texeira Santana ${ }^{a, c}$ Claudia Farias Benjamim ${ }^{b} \quad$ Camila Guerra Martinez $^{a, c}$ \\ Eleonora Kurtenbacha, c Christina Maeda Takiya ${ }^{a}$ Robson Coutinho-Silva ${ }^{a, c}$ \\ ${ }^{a}$ Instituto de Biofísica Carlos Chagas Filho, and b ${ }^{\text {b }}$ epartamento de Farmacologia, Instituto de Ciências Biomédicas, \\ Universidade Federal do Rio de Janeiro, and 'Instituto Nacional de Pesquisa Translacional em Saúde e Ambiente na Região \\ Amazônica, Rio de Janeiro, Brazil
}

\section{Key Words}

P2X7 receptor · Sepsis · Extracellular ATP · Inflammation ·

Macrophages $\cdot$ Neutrophils

\begin{abstract}
Background: Sepsis is associated with high mortality rates in intensive care units worldwide and represents a systemic inflammatory response to infection. P2X7 is an ionotropic purine receptor with known proinflammatory activity. Here, we investigated the role of the $\mathrm{P} 2 \mathrm{X} 7$ receptor in sepsis induced by cecal ligation and puncture (CLP). Methods: Wildtype (WT) and P2X7KO (P2X7 null) mice were subjected to CLP and their survival was monitored for 7 days. Blood, peritoneal wash and lungs were collected $24 \mathrm{~h}$ after CLP and used to measure bacterial load, immune cell infiltration, nitric oxide (NO), cytokine levels, and peritoneal cell death and to assess lung injury. Results: P2X7KO mice showed significantly increased survival 7 days after CLP (30\% compared to $60 \%$ in WT animals) accompanied by an overall attenuated inflammatory response, with decreased cell recruitment to the peritoneum, no or limited increases in the levels of NO and proinflammatory cytokines (IL-1 $\beta$, IL-6, IL-12, IL-17, and IL-4), reduced peritoneal cell apoptosis, and less pronounced lung infiltration and morphological changes. Conclusions: Our data show the P2X7 receptor is required for the develop-
\end{abstract}

ment of the inflammatory response associated with sepsis and support the notion that $\mathrm{P} 2 \mathrm{X} 7$ receptor is a valid therapeutic target against inflammatory diseases.

(c) 2015 S. Karger AG, Basel

\section{Introduction}

Sepsis is the major cause of death in intensive care units worldwide and the mortality rate of severe sepsis reaches $60 \%$ in some parts of the USA $[1,2]$. Sepsis is a complex condition currently defined as a systemic inflammatory response syndrome triggered by an infectious agent, often leading to shock, multiple organ failure and death $[2,3]$.

Tissue damage caused by sepsis occurs due to an exacerbated production of reactive oxygen and nitrogen species, infiltration of inflammatory cells recruited by chemokines and the presence of proinflammatory cytokines [3-5]. Together, these phenomena generate an ineffective response to the infectious agent, which continues to spread and multiply $[4,5]$. Specific cytokines, including IL-6, IL- $1 \beta$ and TNF- $\alpha$, appear to be involved in sepsis development, because serum levels of these inflammatory mediators increase $24 \mathrm{~h}$ after the induction of polymicrobial sepsis by cecal ligation and puncture (CLP) [6].

\section{KARGER 125}

(c) 2015 S. Karger AG, Base

$1662-811 \mathrm{X} / 15 / 0074-0417 \$ 39.50 / 0$

E-Mail karger@karger.com

www.karger.com/jin
Prof. Robson Coutinho-Silva

Instituto de Biofísica Carlos Chagas Filho - UFRJ

Edifício do Centro de Ciências da Saúde, Bloco G., Av. Carlos Chagas Filho, 373

Cidade Universitária, Ilha do Fundão, Rio de Janeiro, RJ 21941-902 (Brazil)

E-Mail rcsilva@biof.ufrj.br 
Uncontrolled activation of the innate immune system, including cellular activation, is one of the main components involved in the physiopathology of sepsis $[4,5]$. Macrophages and neutrophils are key effector cells of the innate immune system that play an important role in sepsis resolution, although they also contribute to increase the disease severity [6-8]. They are myeloid cell populations from the innate immune system that recognize microbes and initiate the inflammatory process, kill bacteria and secrete chemokines to attract other cells to the inflamed site $[6,7]$.

The P2X7 receptor is expressed in many cell types, including immune system cells such as macrophages, mast cells, lymphocytes, and dendritic cells, and it plays an important role in inflammatory processes, having emerged as an attractive therapeutic target for the treatment of inflammatory diseases $[9,10]$. P2X are ionotropic receptors activated by extracellular ATP (eATP) [11], which can act as a mediator of intercellular communication, conveying a 'danger' signal when found in sufficiently high concentrations [12]. Modulation of inflammatory responses by eATP is partly due to indirect chemotactic properties of this signaling mediator, because eosinophils and neutrophils migrate into tissues with high eATP concentrations $[9,12]$. Activation of the P2X7 receptor by eATP induces NLRP3 inflammasome assembly and activation of caspase- 1 , which cleaves pro-IL- $1 \beta$ into mature IL- $1 \beta$, which is then released and promotes inflammation [13]. Besides that, the P2X7 receptor activation also induces extracellular release of ATP through this particular receptor [14], potentiating inflammatory events such as cell death by apoptosis or necrosis [9].

The P2X7 receptor plays a role in responses to infections by intracellular bacteria such as chlamydia and mycobacteria, whose survival in host cells is increased in the absence of this receptor [15-17]. Despite the importance of the P2X7 receptor in inflammatory responses to pathogens, it is not established whether this receptor has a role in sepsis-induced inflammation.

Here, we use a mouse model to investigate the role of $\mathrm{P} 2 \mathrm{X} 7$ receptors during sepsis. We show that, in the absence of the $\mathrm{P} 2 \mathrm{X} 7$ receptor, the innate immune response that is a hallmark of sepsis is attenuated systemically, resulting in increased mouse survival and reduced inflammatory burst.

\section{Materials and Methods}

\section{Animals}

In this study, we used male 2-month-old C57BL/6 mice, either WT or null mutants for the P2X7 receptor (P2X7KO). The animals were manipulated following the guidelines of the ethical commit- tee of the Federal University of Rio de Janeiro (IBCCF039 document) and were maintained in an acclimatized animal facility with sterilized water and commercial food. P2X7KO mice (originally from Jackson Laboratory, USA) were maintained in the transgenic animal house of the Federal University of Rio de Janeiro.

\section{Cecal Ligation and Puncture}

WT and P2X7KO mice were anesthetized by intraperitoneal injection of a mixture of $112.5 \mathrm{mg} / \mathrm{kg}$ ketamine and $7.5 \mathrm{mg} / \mathrm{kg}$ xylazine (both from König Laboratories, Avellaneda, Argentina) and then subjected to laparotomy, with the production of an abdominal incision of $1 \mathrm{~cm}$ from which the cecum was exposed. Feces were gently pushed to the end of the cecum, which was then ligated below the ileum-cecal junction, forming a pouch. Two punctures were made with a $21 \mathrm{G}$ needle, and feces were gently squeezed out to induce polymicrobial peritonitis. The cecum was then returned to the peritoneal cavity and the abdominal wall was closed by suture. Sham-operated animals had their cecum exposed but not punctured and henceforth are referred to as 'Sham'.

Mouse Sample Collection and Estimation of Bacterial Load

Blood samples were collected from the ocular plexus of operated mice under anesthesia $24 \mathrm{~h}$ after CLP. Then, the animals were killed before collection of a peritoneal wash and lungs. Peritoneal washes were kept on ice and mouse lungs were fixed in $10 \%$ formalin.

Blood samples were diluted to 1:500 in PBS, and $20 \mu \mathrm{l}$ of this suspension were seeded on Agar plates (Sigma-Aldrich, USA), which were then incubated for $48 \mathrm{~h}$ at $37^{\circ} \mathrm{C}$. After incubation, the colonies were counted and the number of bacterial colony-forming units (CFU) in original blood samples was calculated; this measure was used as an estimate of the bacterial load in septic animals.

\section{Nitric Oxide Quantification}

Nitric oxide (NO) levels in peritoneal wash and in blood were estimated by using the Griess reagent method [18]. Briefly, samples were spun at $500 \mathrm{~g}$ for $15 \mathrm{~min}$ at room temperature and $100 \mu \mathrm{l}$ of supernatant was added to $100 \mu \mathrm{l}$ of the Griess reagent, consisting of $1 \%$ sulfanilamide (Sigma-Aldrich, USA) and 0.1\% N-1-naftiletilenediamine in 5\% $\mathrm{H} 3 \mathrm{PO}$. After a 15 -min incubation period, color development was detected by absorbance at $570 \mathrm{~nm}$ in a SpectraMax-M5e (Molecular Devices, USA).

\section{Peritoneal Cell Counting}

Peritoneal washes were centrifuged at $500 \mathrm{~g}$ for $15 \mathrm{~min}$, the supernatant was removed and the pellet of cells was resuspended in 1,000 $\mu$ l of DMEM (Gibco; Life Technologies, USA). The number of viable cells in this suspension was determined by direct cell counting in a hemocytometer, using the exclusion dye trypan blue. After cell counting, $4 \times 10^{4}$ cells were seeded onto slides using a cytospin (750 $\mathrm{g}$ for $5 \mathrm{~min}$ ). The slides were stained using May-Grünwald Giemsa and observed in a light microscope. Stained cells were classified as mononuclear or polymorphonuclear.

\section{Peritoneal Cell Phenotyping}

Viable cells in the peritoneal wash were counted as previously described and plated on 96-well plates at a density of $2 \times 10^{5}$ cells/ well. Samples were then incubated for $1 \mathrm{~h}$ in blocking buffer $(0.25 \%$ 
BSA and $1 \%$ horse serum in PBS) and labeled (for 30 min at $4{ }^{\circ} \mathrm{C}$ ) with one of the following antibodies: anti-CD4-Alexa488, antiCD8-PE, anti-CD11b-PE or anti-Ly6G-FITC (all from e-Bioscience) used at a final concentration of $1 \mu \mathrm{g} / \mathrm{ml}$ (in 1\% BSA in PBS). After labeling, the cells were washed twice in 1\% BSA in PBS and then analyzed in a FACSCalibur flow cytometer (BD Biosciences, USA). The percentage of positive cells was applied to the total number of cells in each peritoneal wash to produce estimates of absolute numbers of cells from each cell type in individual peritoneal washes.

\section{Cytokine Measurements}

Levels of cytokines IL-1 $\beta$, IL-12, IL-4, IL-10, IL-6, IL-17, TNF- $\alpha$, and TGF $\beta$ were estimated by ELISA (PeproTech, USA) in the peritoneal fluid following the manufacturer's instructions. Briefly, wells were coated with capture anti-cytokine antibodies overnight, washed and then incubated for $2 \mathrm{~h}$ in blocking buffer (10\% horse serum in PBS). After a washing step, samples were added to wells and incubated for $2 \mathrm{~h}$. The plates were then washed, incubated for $2 \mathrm{~h}$ with $0.5 \mu \mathrm{g} / \mathrm{ml}$ of the detection antibody, washed again, and incubated with HRP-Avidin, (1:2,000 dilution) for 30 min. Finally, ABTS [2,2'-azino-di(3-ethylbenzthiazoline-6-sulfonate)] was added, color development was monitored and absorbance was measured in a SpectraMax-M5e (Molecular Devices) at $450 \mathrm{~nm}$. ELISA data analysis was performed using the GraphPad Prism 5.0.

\section{Apoptosis Analysis}

Briefly, cells collected from peritoneal washes as described above $\left(1 \times 10^{5}\right.$ cells/sample) were resuspended in $100 \mu \mathrm{l}$ of Annexin V Binding Buffer (BioLegend, USA), to which FITC Annexin $\mathrm{V}$ and propidium iodide (PI) were added according to the manufacturer's instructions (BioLegend). Samples were gently vortexed, incubated for $15 \mathrm{~min}$ at room temperature in the dark and then analyzed using a FACSCalibur (BD Biosciences).

\section{Histological Processing}

Lungs were collected from operated mice and fixed in $10 \%$ buffered formalin as described above. They were dehydrated in a series of three ethanol solutions (two of $90 \%$ and the last of 100\%) and xylene (100\%) and then embedded in paraffin. Sections of paraffin blocks of embedded organs were stained with hematoxylineosin (HE) as described by Monção-Ribeiro et al. [18] in 2011. Slides were mounted using Entellan ${ }^{\circledR}$ (Merck Millipore, Germany), and samples were imaged on a NIKON E 400 light microscope (Nikon, Japan) coupled with an EVOLUTION digital camera (Media Cybernetics, USA).

\section{Statistical Analysis}

Data were analyzed in GraphPad Prism 5.0 and statistically significant differences between experimental groups were detected using Student's t test $(\mathrm{p}<0.05)$. A Kaplan-Meier analysis was performed to obtain the number of animals at risk. Figures are representative of three or more experiments, and at least 5 animals were used per experimental group for in vivo experiments. Flow cytometry data were analyzed using the WinMDI program (V2.8; Scripps Research Institute, La Jolla, USA). At least 10,000 cells were analyzed for each sample. Unpaired Student's $t$ tests were used for statistical analysis of flow cytometry data.

P2X7 Receptor Participation during Sepsis

\section{Results}

\section{P2X7KO Animals Are Less Susceptible to Sepsis}

\section{Induced by CLP}

We evaluated the sensitivity of WT and P2X7KO animals to CLP-induced sepsis as an initial step to examine whether the $\mathrm{P} 2 \mathrm{X} 7$ receptor has a role in sepsis development. Sepsis was induced by two perforations in the cecum and the survival of operated mice was monitored for 7 days. P2X7KO animals were considerably less sensitive to CLP-induced sepsis compared to WT animals $(60 \%$ overall survival compared to $30 \%$ in the WT), and fewer animals were at risk of death in this group (fig. 1a). To confirm that P2X7KO animals did not express the native $\mathrm{P} 2 \mathrm{X} 7$ receptor, $\mathrm{PCR}$ analysis was performed. The amplification of the native sequence did not occur in P2X7KO animals, in contrast to WT mice (online suppl. fig. 1; for all online suppl. material, see www.karger.com/doi/10.1159/000371388).

The largest number of deaths was observed within $48 \mathrm{~h}$ of sepsis induction (fig. 1a), although death occurred as early as $24 \mathrm{~h}$ after CLP, and the latter time point was chosen for sample collection (blood, peritoneal washes and lungs) to examine early steps in sepsis development in P2X7KO mice. After $24 \mathrm{~h}$ of sepsis induction, high bacteremia $\left(\geq 1 \times 10^{4} \mathrm{CFU} / \mathrm{ml}\right)$ was detected in both $\mathrm{WT}$ and P2X7KO animals (fig. 1b). However, animals without the P2X7 receptor showed fewer circulating bacteria (fig. 1b). A similar profile was also obtained when the bacterial load was estimated in the peritoneal cavity (data not shown).

We quantified, by direct counting, the cells found in a peritoneal wash collected $24 \mathrm{~h}$ after CLP to compare immune system cell recruitment to the peritoneum in WT and P2X7KO animals. Strikingly, immune system cells were recruited to the peritoneum after CLP in the WT group but not in the P2X7KO group (fig. 1c).

\section{Neutrophils and CD8+ T Lymphocytes Were Not \\ Recruited to the Peritoneum in P2X7KO Mice \\ Subjected to CLP}

To investigate which cell types were recruited to the peritoneum after sepsis induction, we performed light microscopy analysis of peritoneal wash cells after cytospin (fig. 2). Increased numbers of polymorphonuclear cells were found in peritoneal washes from WT animals subjected to CLP (fig. 2c, black arrows), while polymorphonuclear cells were not recruited to the peritoneum in P2X7KO animals (fig. 2d, black arrows).

Phenotyping of peritoneal wash cells by flow cytometry (using specific markers of immune system cells) 


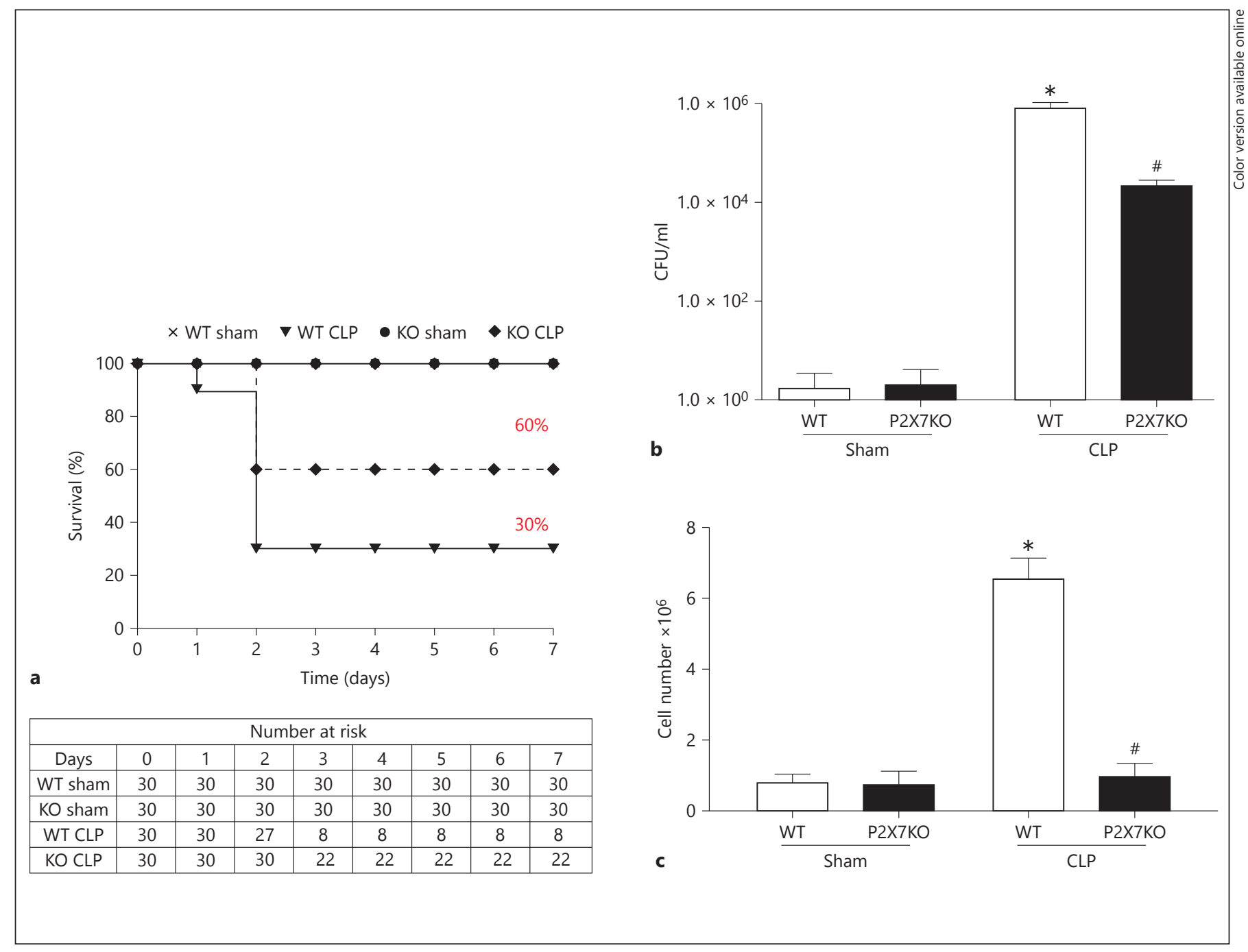

Fig. 1. P2X7KO mice have significantly reduced sensitivity to sepsis induced by CLP. a Animal survival was monitored for 7 days after CLP and a Kaplan-Meier analysis of the number of animals at risk of death was performed. Blood samples and peritoneal washes were collected from animals $24 \mathrm{~h}$ after sepsis induction by CLP, and the number of bacterial CFU was estimated in blood samples (b), while the total number of cells was estimated in peri-

Fig. 2. Fewer neutrophils are observed at the site of inflammation in septic P2X7KO animals. Peritoneal washes were collected $24 \mathrm{~h}$ after sepsis induction by CLP, and the peritoneal cell populations from Sham WT (a) Sham P2X7KO (b), CLP WT (c) and CLP $\mathrm{P} 2 \mathrm{X} 7 \mathrm{KO}$ (d) animals were analyzed by light microscopy. Arrows show neutrophils. Scale bar $=10 \mu \mathrm{m}$. e-h Peritoneal wash cells were also analyzed by flow cytometry using phenotypic antibody markers. Concentrations of Ly6G+ neutrophils (e), CD11b+ toneal washes $(\mathbf{c}){ }^{*} \mathrm{p} \leq 0.05$ : statistically significant difference between treated and control groups (e.g. WT CLP vs. WT Sham); $\# \mathrm{p} \leq 0.05$ : statistically significant difference between mouse strains (e.g. WT CLP vs. P2X7KO CLP). Charts represent results from 5 independent experiments ( $n=5$ mice per group) and the survival curve represents results from 3 independent experiments $(n=10$ mice per group). 


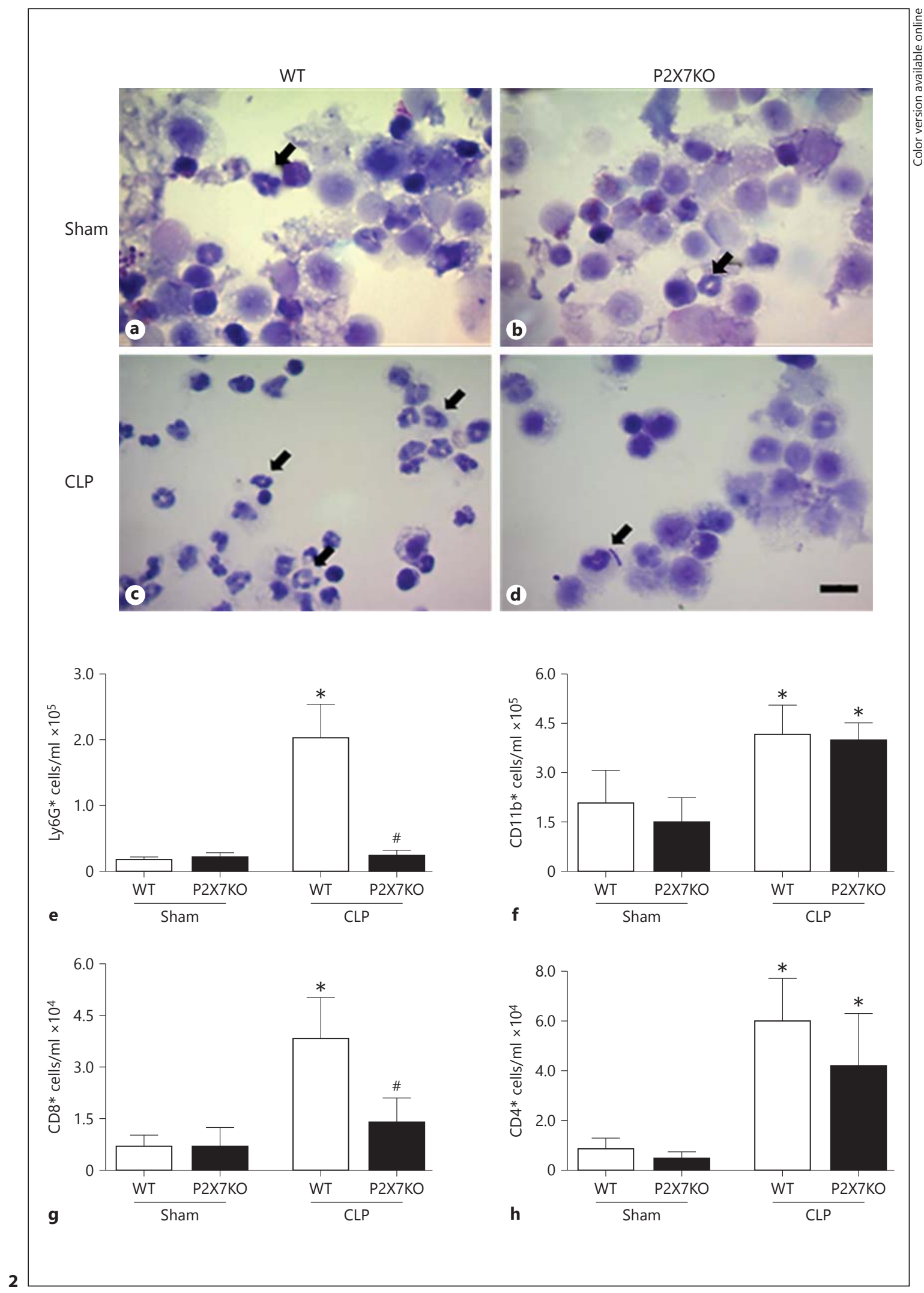




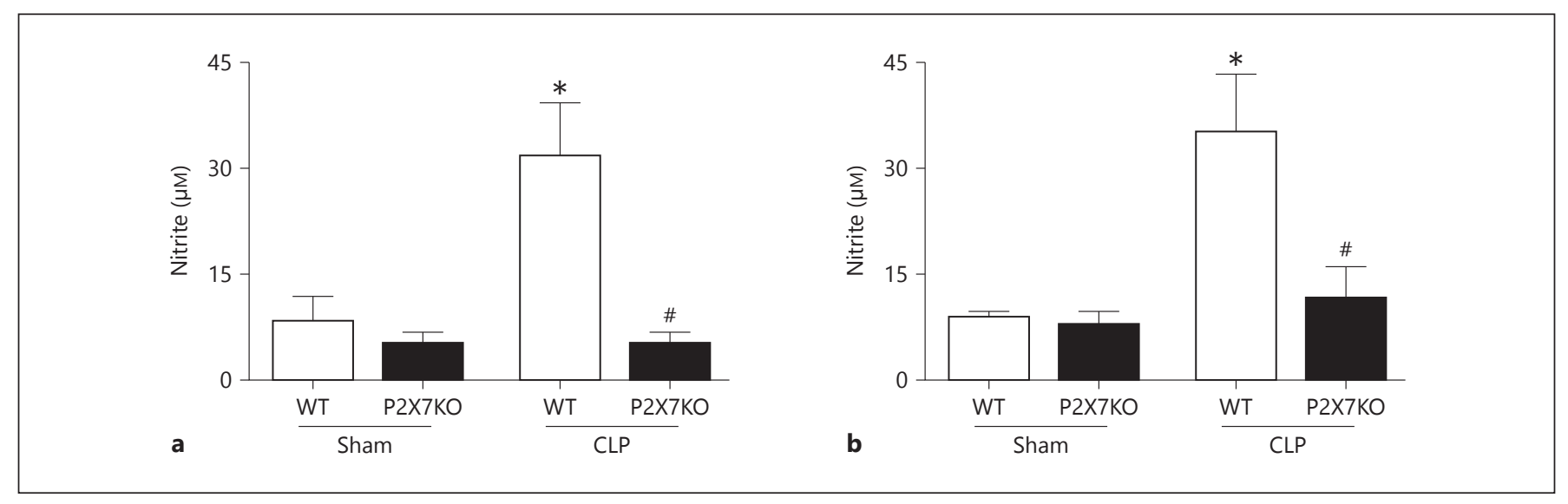

Fig. 3. NO production is reduced after sepsis in $\mathrm{P} 2 \mathrm{X} 7 \mathrm{KO}$ mice. Peritoneal washes and blood were collected from mice $24 \mathrm{~h}$ after sepsis induction by CLP, and NO levels in the peritoneal wash (a) and in blood (b) were estimated indirectly by nitrite quantification using the Griess reagent method. ${ }^{*} \mathrm{p} \leq 0.05$ : statistically sig- nificant difference between treated and control group (e.g. WT CLP vs. WT Sham); \# p $\leq$ 0.05: statistically significant difference between mouse strains (e.g. WT CLP vs. P2X7KO CLP). Graphs represent results from 3 replicate experiments $(n=5$ mice per experiment). showed CLP induction led to the recruitment of neutrophils (Ly6G+ cells) to the peritoneum only in the WT septic animals (fig. 2e). The number of peritoneal CD8+ $\mathrm{T}$ lymphocytes also increased significantly after sepsis only in WT mice (fig. 2g). In contrast, the numbers of mononuclear cells $(\mathrm{CD} 11 \mathrm{~b}+$, represented mainly by macrophages) and of CD4+ T lymphocytes increased to similar extents both in WT (fig. 2f) and P2X7KO animals (fig. 2h) after sepsis induction compared to Sham-operated controls.

\section{Inflammatory Mediators Are Reduced in Septic P2X7KO Mice}

To produce a broad view of the inflammatory scenario induced by CLP-mediated sepsis in WT and P2X7KO mice, we measured the levels of NO, a key inflammatory mediator during sepsis, and of pro- and anti-inflammatory cytokines in samples collected from mice $24 \mathrm{~h}$ after CLP.

NO levels (estimated indirectly by measuring nitrite levels) increased after sepsis induction in WT mice but not in P2X7KO mice (fig. 3b), both in peritoneal washes (fig. 3a) and in blood (fig. 3b). Cytokine levels were measured in peritoneal washes to assess localized cytokine activity at the initial site of inflammation. The levels of IL- $1 \beta$, a proinflammatory cytokine intimately related to $\mathrm{P} 2 \mathrm{X} 7$ receptor activation, increased after sepsis induction in WT and P2X7KO mice, although higher IL-1 $\beta$ levels were observed in WT animals (fig. 4a). An important cytokine whose increased expression has been asso- ciated with higher sepsis severity is TNF- $\alpha[3,5]$, and levels of this cytokine were higher in both WT and P2X7KO mice after sepsis induction compared to those observed in Sham animals (fig. 4b). IL-6 is an acute proinflammatory cytokine regarded as one of the main generators of the systemic inflammatory response in sepsis $[3,4]$. CLP induced IL-6 production both in WT and P2X7KO mice, but IL-6 levels in P2X7KO mice subjected to CLP were significantly lower compared to those observed in WT mice (fig. 4c). CLP-induced sepsis led to IL-17 and IL-12 secretion only in WT animals (fig. 4d, e), while IL-4 levels did not change significantly after sepsis induction (fig. 4f).

Finally, the levels of the anti-inflammatory mediators TGF- $\beta$ and IL-10 increased after sepsis in WT mice (fig. 5a) but not in P2X7KO mice (fig. 5b).

\section{Cell Death Was Not Observed in Peritoneal Cells from P2X7KO Mice}

The systemic inflammatory response generated by sepsis results in cell death (by apoptosis and necrosis) associated with tissue and organ injury. Assessment of cell death by apoptosis in peritoneal washes using Annexin V and PI staining $24 \mathrm{~h}$ after CLP showed an increased percentage of late apoptotic/necrotic cells in WT but not in P2X7KO animals (fig. 6a). The total number of apoptotic cells (Annexin $\mathrm{V}^{+} \mathrm{PI}^{-}$) increased in both WT and P2X7KO animals after CLP (fig. 6b), whereas the number of late apoptotic/necrotic cells increased only in WT animals (fig. 6c). 


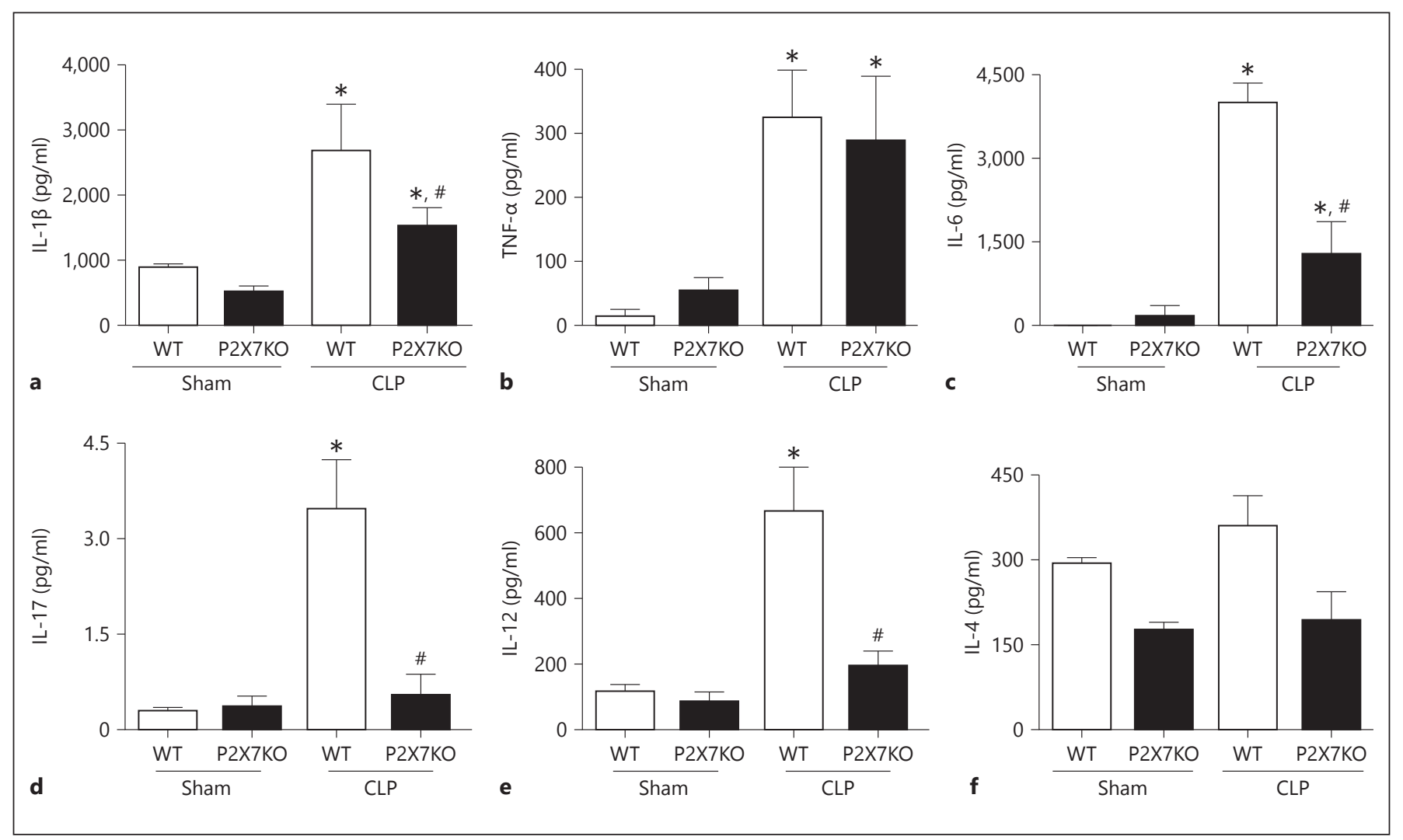

Fig. 4. The induction of proinflammatory cytokine production in the peritoneum was reduced in $\mathrm{P} 2 \mathrm{X} 7 \mathrm{KO}$ mice after sepsis induced by CLP. Levels of the proinflammatory cytokines IL-1 $\beta$ (a), TNF- $\alpha$ (b), IL-6 (c), IL-17 (d), IL-12 (e), and IL-4 (f) in peritoneal washes collected $24 \mathrm{~h}$ after CLP were estimated by ELISA. ${ }^{*} \mathrm{p} \leq 0.05$ : sta- tistically significant differences between treated and control groups (e.g. WT CLP vs. WT Sham); \# p $\leq$ 0.05: statistically significant difference between mouse strains (e.g. WT CLP vs. P2X7KO CLP). Graphs represent results from 3 independent experiments $(n=5$ mice per experiment).
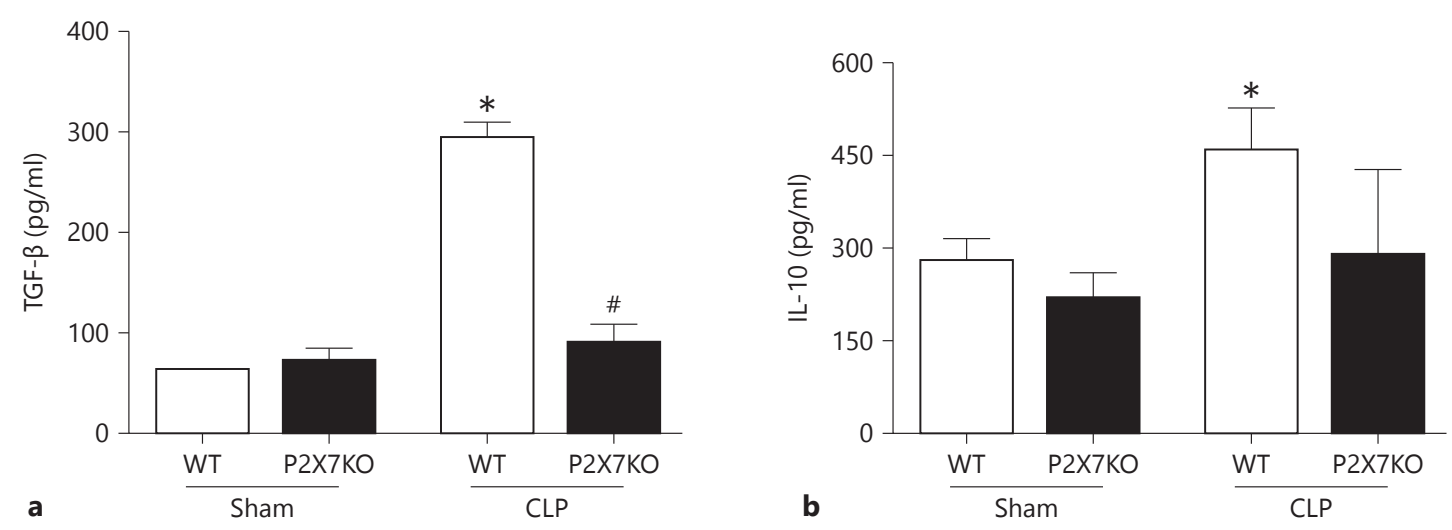

Fig. 5. Production of anti-inflammatory cytokines is impaired in P2X7KO mice after sepsis induction by CLP. The levels of the antiinflammatory cytokines TGF- $\beta$ (a) and IL-10 (b) in peritoneal washes collected $24 \mathrm{~h}$ after CLP were measured by ELISA. ${ }^{*} \mathrm{p} \leq$ 0.05: statistically significant difference between treated and control groups (e.g. WT CLP vs. WT Sham); \# $\mathrm{p} \leq 0.05$ : statistically significant difference between mouse strains (e.g. WT CLP vs. $\mathrm{P} 2 \mathrm{X} 7 \mathrm{KO}$ CLP). Graphs represent results from 3 independent experiments ( $n=5$ mice per experiment). 


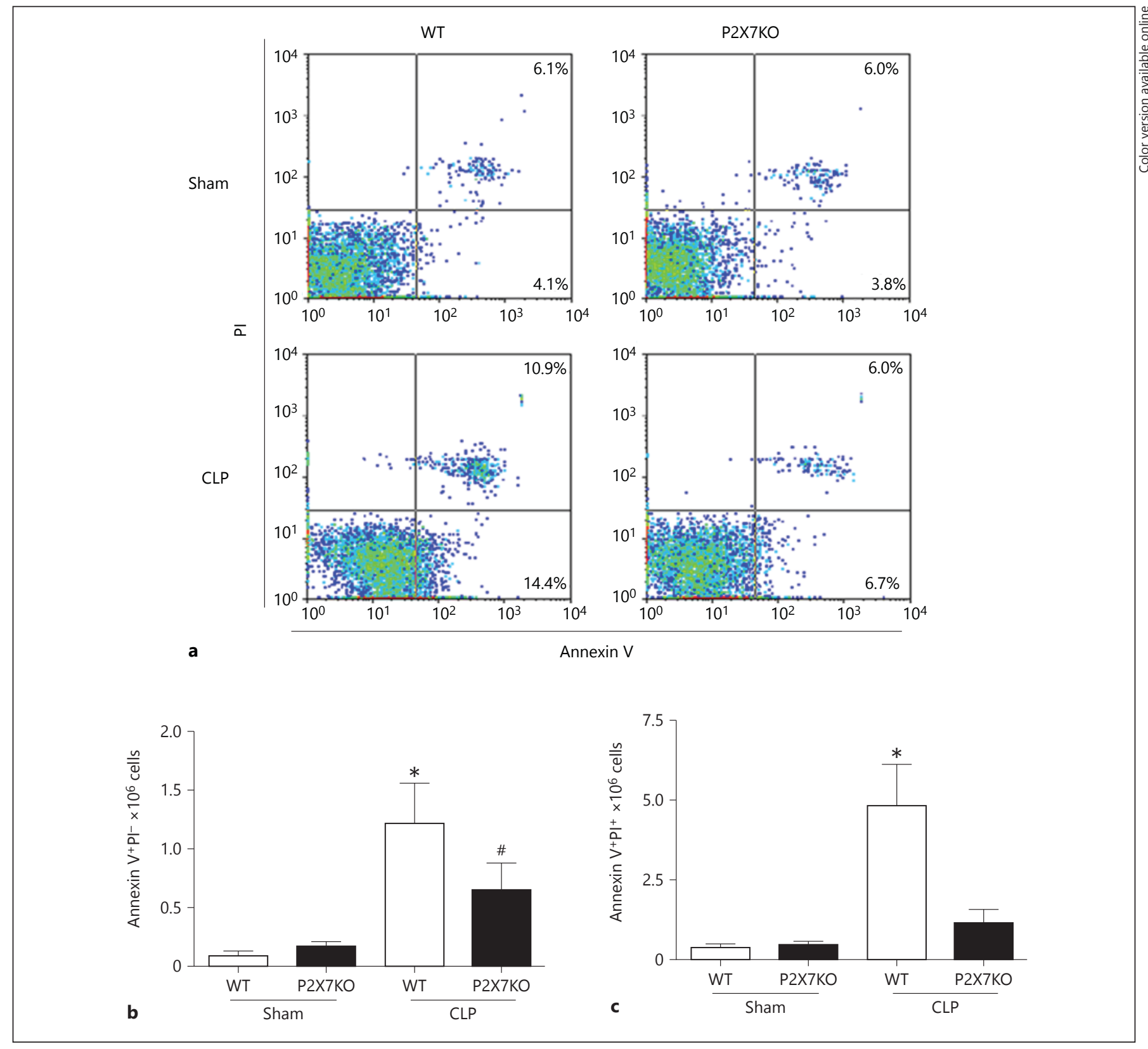

Fig. 6. Cell death by apoptosis is reduced in P2X7KO animals after sepsis induction by CLP. Apoptosis was assessed in peritoneal washes collected $24 \mathrm{~h}$ after sepsis induction, using combined Annexin V and PI staining. There was an increase in early apoptotic cells (Annexin $\mathrm{V}^{+} \mathrm{PI}^{-}$; a) after CLP in WT and $\mathrm{P} 2 \mathrm{X} 7 \mathrm{KO}$ mice. An increase in late apoptotic/necrotic cells (Annexin $\mathrm{V}^{+} \mathrm{PI}^{+} ; \mathbf{a}$ ) was also observed, but only in WT mice, after CLP. The total number of early apoptotic cells (Annexin $\mathrm{V}^{+} \mathrm{PI}^{-} ; \mathbf{b}$ ) and late apoptotic/necrotic (Annexin $\mathrm{V}^{+} \mathrm{PI}^{+}$; c) were also counted. ${ }^{*} \mathrm{p} \leq 0.05$ : statistically significant difference between treated and control groups (e.g. WT CLP vs. WT Sham). Plots represent results from 3 independent experiments $(\mathrm{n}=5$ mice per experiment).

\section{Lungs from P2X7KO Mice Were Less Damaged after the Induction of Sepsis}

To examine the extent of tissue damage produced by CLP-induced sepsis in P2X7KO mice, we performed histological analysis of mouse lungs collected $24 \mathrm{~h}$ after CLP.
The changes in lung tissues $24 \mathrm{~h}$ after CLP were most evident in WT animals compared to P2XKO animals. These included the enlargement of the alveolar septa (alveolitis), with increased numbers of inflammatory cells in the septa (vascular congestion) and lung cell thickening 


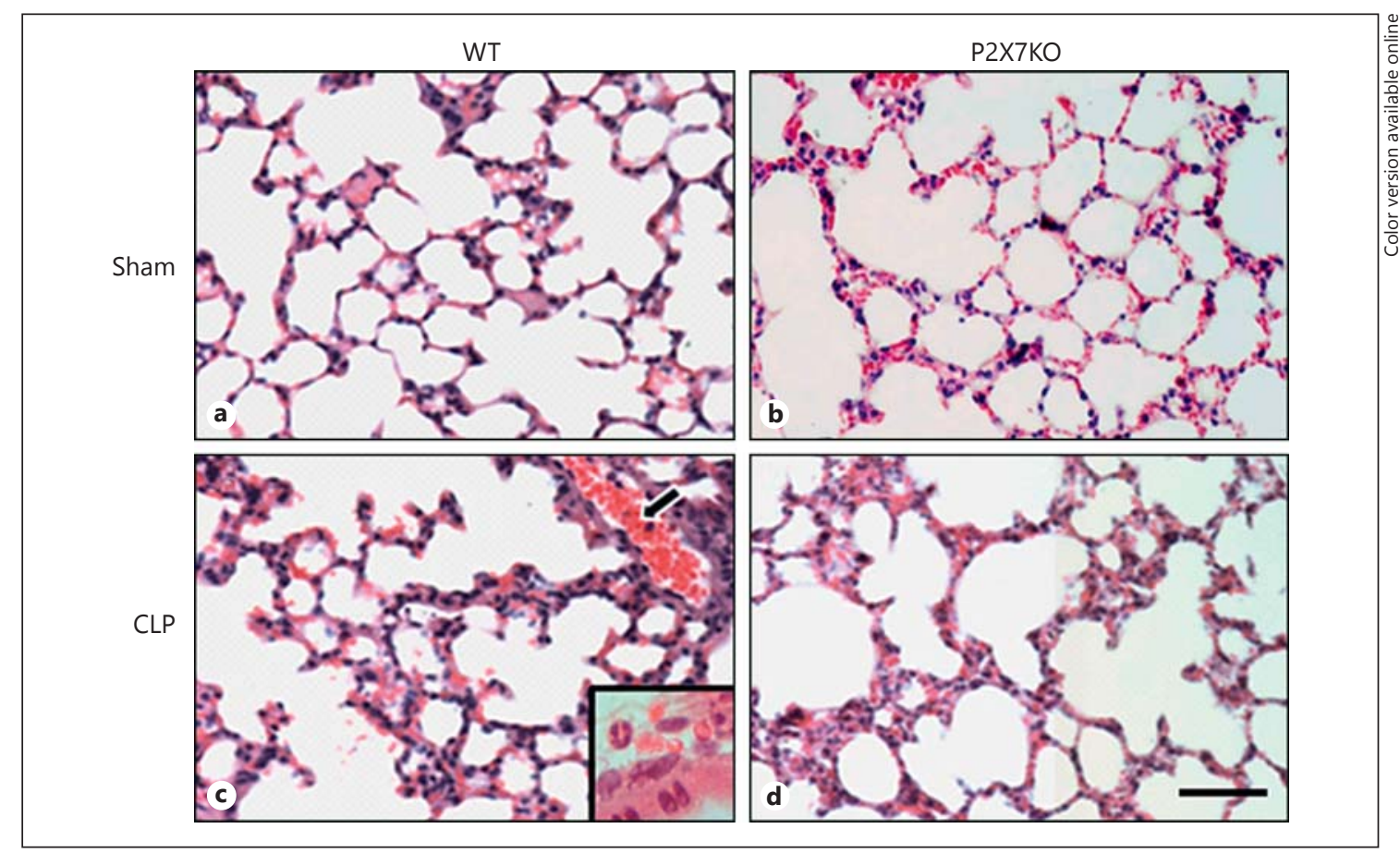

Fig. 7. Lung tissue stained with HE portrays less damage in septic P2X7KO animals. After $24 \mathrm{~h}$ of sepsis induction the lungs of the animals were collected and fixed in paraffin. Cuts were made and pro-

(fig. 7c). We could also observe blood vessels in some areas, probably carrying inflammatory cells to infiltrate lung tissues (fig. 7c); in a major magnification, inflammatory cells were visible (fig. $7 \mathrm{c}$, inset).

\section{Discussion}

Sepsis is characterized by an exacerbated inflammatory response to infection and remains a serious problem in intensive care units worldwide. Purinergic receptors are involved in several inflammatory processes such as the killing of intracellular bacterial pathogens and lipopolysaccharide (LPS)-induced lung injury [15-20]. However, little is known about their involvement in sepsis. Here, we investigated inflammation during CLP-induced sepsis using a variety of methods. Taken together, in the absence of the P2X7 receptor our findings show attenuation in systemic inflammation that is central to sepsis development. As a consequence, $\mathrm{P} 2 \mathrm{X} 7 \mathrm{KO}$ mice are significantly less sensitive to CLP-induced sepsis.

Currently, ATP is considered a chemotactic factor for neutrophils and macrophages [9], and it has been shown that the P2X7 receptor releases ATP, as well as being acti- cessed for HE staining. This figure shows the lung slices of septic WT animals with an inset showing inflammatory cells (c), P2X7KO animals (d) and their respective control groups $(\mathbf{a}, \mathbf{b})$. Scale bar $=50 \mu \mathrm{m}$. vated by this nucleotide [14]. Thus, P2X7KO septic animals might recruit fewer inflammatory cells to sites of inflammation, as shown in the present work, due to reduced eATP levels $[12,21]$. Neutrophils represent one of the major inflammatory cell populations responsible for the immune response during sepsis [7, 9]. Infiltration of the site of infection by neutrophils helps to control the infection but may also compromise the effectiveness of the immune response to bacterial pathogens, as observed during $M y$ cobacterium tuberculosis and Listeria monocytogenes infections, where macrophage, but not neutrophil, activity is important for the establishment of an effective immune response $[8,22]$. Here, we showed an increase in the number of neutrophils at the site of inflammation during sepsis in WT but not in P2X7KO mice. However, mice from both animal strains displayed similarly increased numbers of peritoneal macrophages after sepsis induction. Thus, similarly to the situation described for bacterial infections, macrophage activity unrestrained by inhibitory neutrophil infiltration is, at least in part, responsible for the greater resistance to sepsis in $\mathrm{P} 2 \mathrm{X} 7 \mathrm{KO}$ mice.

In our model of sepsis, we observed NO production at the site of initial infection and inflammation only in WT mice (only in the presence of the $\mathrm{P} 2 \mathrm{X} 7$ receptor). It is 
likely that this phenomenon is related to reduced macrophage performance and survival in WT mice subjected to CLP, since high NO levels during sepsis can impair macrophage function through a reduction in cytokine production and macrophage apoptosis $[22,23]$. On the other hand, $\mathrm{NO}$ also induces neutrophil activation at the site of infection, triggering a proinflammatory response [24], which is likely to increase sepsis severity. In agreement with this hypothesis, $\mathrm{P} 2 \mathrm{X} 7 \mathrm{KO}$ mice do not produce NO $24 \mathrm{~h}$ after sepsis induction and are less likely to develop severe sepsis. In the presence of LPS and IFN- $\gamma$, neutrophils secrete TNF- $\alpha$ and produce NO, leading to an increase in ROS, a reduction of apoptosis and higher rates of phagocytosis in neutrophils [6].

A mixed inflammatory response was observed during sepsis with the participation of pro- and anti-inflammatory cytokines. The absence of the $\mathrm{P} 2 \mathrm{X} 7$ receptor impairs the inflammasome-dependent production of IL- $1 \beta$, which may lead to a decreased production of other cytokines [13]. Some cytokines such as TNF- $\alpha$ and IL- 6 are markers of sepsis $[25,26]$. TNF- $\alpha$ may induce a 'shock-like' syndrome and is involved with the severity of the septic shock, but the role of the P2X7 receptor in its production is controversial $[27,28]$. Herein, the absence of the P2X7 receptor did not affect the increase in TNF- $\alpha$ production. Through the P2X7 receptor, eATP mediates the release of IL- 6 in microglia, which was also diminished in the absence of this receptor [29], contributing to the onset of sepsis. Neutrophils produce high levels of IL-17, which can induce the production of other inflammatory cytokines such as IL-6 and promote the interplay between the activities of phagocytes and lymphocytes [30]. The neutralization of IL-17A increases animal survival and reduces bacteremia and cytokine production, and it has also been reported that ATP induces a TH17 phenotype [31-33], which is in accordance with our data obtained with P2X7KO mice. The cytokine IL-12 can be produced by $\gamma \delta$-lymphocytes and dendritic cells during sepsis [34]. Indeed, $24 \mathrm{~h}$ after sepsis there is an increase in IL-12 levels in the peritoneal wash of WT animals subjected to CLP, and this cytokine increase has already been associated with protection against sepsis [35], although our results in P2X7KO mice do not support this hypothesis. Both the levels of IL-17 and IL-12 shown here are increased only in the P2X7KO. The compensatory anti-inflammatory response observed during sepsis is orchestrated by the cytokines IL-10 and TGF- $\beta$, which activate cells of the immune system to prevent the production of inflammatory mediators $[36,37]$. TGF- $\beta$ also promotes both pro-and anti-inflammatory effects, since TGF- $\beta$ and IL-6 together may promote the differentiation of TH17 cells, which can have proinflammatory and cytotoxic effects, enhancing pathogen elimination [38].

Cell death, especially by apoptosis, is one of the effects of the inflammatory burst during sepsis [26], and high cell death is observed in leukocytes and lymphoid organs [39, 40]. We show here that the absence of the P2X7 receptor attenuated late apoptosis in infiltrating cells [41]. The P2X7 receptor has been associated with cell death, and its deficiency has reduced apoptosis in some models $[18,42]$, which could contribute to our findings.

The lung is a widely studied shock organ known to be affected in CLP-induced sepsis [43]. Thus, it is not surprising that the protection against sepsis development observed in the absence of the $\mathrm{P} 2 \mathrm{X} 7$ receptor was also evident in the lungs of $\mathrm{P} 2 \mathrm{X} 7 \mathrm{KO}$ mice subjected to CLP, which displayed fewer polymorphonuclear cells and milder structural changes than the lungs of WT mice subjected to CLP. These results are in agreement with our own published data showing the P2X7 receptor contribution to lung injury induced by LPS [18].

Taken together, our data suggest the P2X7 receptor is an important component of the immune response during sepsis, because the P2X7KO mice have attenuated sepsisassociated inflammation and increased animal survival. This effect is probably due to the ability of the P2X7 receptor to promote cell recruitment to the site of infection and also to the increased $\mathrm{P} 2 \mathrm{X} 7$ receptor-dependent production of inflammatory mediators at this site, resulting in higher sepsis severity in WT animals. Further studies are now necessary to address the modulation of P2X7 function during sepsis and bacterial infections. Our results add to the increasing data in support of the use of the P2X7 receptor as a pharmacological target in adjuvant therapies against severe inflammatory conditions such as sepsis.

\section{Acknowledgments}

This work was supported by funds from the Conselho Nacional de Desenvolvimento Cientifico e Tecnológico do Brasil (CNPq), Coordenação de Aperfeiçoamento de Pessoal de Nível Superior (CAPES), the Programa de Núcleos de Excelência (PRONEX), Fundação de Amparo à Pesquisa do Estado do Rio de Janeiro (FAPERJ), and the Instituto Nacional de Ciência e Tecnologia para Pesquisa Translacional em Saúde e Ambiente na Região Amazôni$\mathrm{ca}$ (INPeTAm/UFRJ). This study was approved and partially funded by the Ciências sem Fronteiras Federal Government Program.

\section{Disclosure Statement}

The authors have no financial conflicts of interest to declare.
Santana/Benjamim/Martinez/ Kurtenbach/Takiya/Coutinho-Silva 


\section{References}

$>1$ Angus DC, Linde-Zwirble WT, Lidicker J, Cl- 17 Coutinho-Silva R, Monteiro da CC, Persechiermont G, Carcillo J, Pinsky MR: Epidemiology of severe sepsis in the United States: analysis of incidence, outcome, and associated costs of care. Crit Care Med 2001;29:1303-1310.

-2 Namas R, Zamora R, Namas R, An G, Doyle J, Dick TE, et al: Sepsis: something old, something new, and a systems view. J Crit Care 2012;27:314-311.

$>3$ Bone RC: Sir Isaac Newton, sepsis, SIRS, and 19 CARS. Crit Care Med 1996;24:1125-1128.

$\checkmark 4$ Hotchkiss RS, Karl IE: The pathophysiology and treatment of sepsis. N Engl J Med 2003; 348:138-150

$\checkmark 5$ Cohen J: The immunopathogenesis of sepsis. Nature 2002;420:885-891.

6 Nathan C: Neutrophils and immunity: challenges and opportunities. Nat Rev Immunol 2006;6:173-182.

7 Serbina NV, Jia T, Hohl TM, Pamer EG: Monocyte-mediated defense against microbial pathogens. Annu Rev Immunol 2008;26: 421-452.

$>8$ Shi C, Hohl TM, Leiner I, Equinda MJ, Fan X, Pamer EG: Ly6G+ neutrophils are dispensable for defense against systemic Listeria monocytogenes infection. J Immunol 2011; 187:5293-5298.

$>9$ Trautmann A: Extracellular ATP in the immune system: more than just a 'danger signal'. Sci Signal 2009;2:e6.

$>10$ Lenertz LY, Gavala ML, Zhu Y, Bertics PJ: Transcriptional control mechanisms associated with the nucleotide receptor P2X7, a critical regulator of immunologic, osteogenic, and neurologic functions. Immunol Res 2011; 50:22-38.

$>11$ Burnstock G: Introductory overview of purinergic signalling. Front Biosci (Elite Ed) 2011; 3:896-900.

-12 Bours MJ, Swennen EL, Di VF, Cronstein BN, Dagnelie PC: Adenosine 5'-triphosphate and adenosine as endogenous signaling molecules in immunity and inflammation. Pharmacol Ther 2006;112:358-404.

13 Martinon F, Mayor A, Tschopp J: The inflammasomes: guardians of the body. Annu Rev Immunol 2009;27:229-265.

14 Pellegatti P, Falzoni S, Donvito G, Lemaire I, Di VF: P2X7 receptor drives osteoclast fusion by increasing the extracellular adenosine concentration. FASEB J 2011;25:1264-1274.

-15 Darville T, Welter-Stahl L, Cruz C, Sater AA, Andrews CW Jr, Ojcius DM: Effect of the purinergic receptor $\mathrm{P} 2 \mathrm{X} 7$ on Chlamydia infection in cervical epithelial cells and vaginally infected mice. J Immunol 2007;179:3707-3714.

16 Santos AA Jr, Rodrigues-Junior V, Zanin RF, Borges TJ, Bonorino C, Coutinho-Silva R, et al: Implication of purinergic $\mathrm{P} 2 \mathrm{X} 7$ receptor in M. tuberculosis infection and host interaction mechanisms: a mouse model study. Immunobiology 2013;218:1104-1112. ni PM, Ojcius DM: The role of $\mathrm{P} 2$ receptors in controlling infections by intracellular pathogens. Purinergic Signal 2007;3:83-90.

18 Monção-Ribeiro LC, Cagido VR, Lima-Mu$\operatorname{rad}$ G, Santana PT, Riva DR, Borojevic R, et al: Lipopolysaccharide-induced lung injury: role of P2X7 receptor. Respir Physiol Neurobiol 2011;179:314-325.

9 de Campos NE, Marques-da-Silva C, Correa G, Castelo-Branco MT, de Souza HS, Coutinho-Silva R: Characterizing the presence and sensitivity of the P2X7 receptor in different compartments of the gut. J Innate Immun 2012;4:529-541.

20 Di VF, Chiozzi P, Ferrari D, Falzoni S, Sanz JM, Morelli A, et al: Nucleotide receptors: an emerging family of regulatory molecules in blood cells. Blood 2001;97:587-600.

21 Myrtek D, Idzko M: Chemotactic activity of extracellular nucleotides on human immune cells. Purinergic Signal 2007;3:5-11.

22 Mishra BB, Rathinam VA, Martens GW, Martinot AJ, Kornfeld H, Fitzgerald KA, et al: Nitric oxide controls the immunopathology of tuberculosis by inhibiting NLRP3 inflammasome-dependent processing of IL-1 $\beta$. Nat Immunol 2013;14:52-60.

23 Giamarellos-Bourboulis EJ, Routsi C, Plachouras D, Markaki V, Raftogiannis M, Zervakis D, et al: Early apoptosis of blood monocytes in the septic host: is it a mechanism of protection in the event of septic shock? Crit Care 2006;10:R76

24 Benjamim CF, Silva JS, Fortes ZB, Oliveira MA, Ferreira SH, Cunha FQ: Inhibition of leukocyte rolling by nitric oxide during sepsis leads to reduced migration of active microbicidal neutrophils. Infect Immun 2002;70: 3602-3610.

25 Herzum I, Renz H: Inflammatory markers in SIRS, sepsis and septic shock. Curr Med Chem 2008;15:581-587.

26 Buras JA, Holzmann B, Sitkovsky M: Animal models of sepsis: setting the stage. Nat Rev Drug Discov 2005;4:854-865.

27 Hide I, Tanaka M, Inoue A, Nakajima K, Kohsaka S, Inoue K, et al: Extracellular ATP triggers tumor necrosis factor-alpha release from rat microglia. J Neurochem 2000;75:965-972.

28 Hasko G, Kuhel DG, Salzman AL, Szabo C: ATP suppression of interleukin-12 and tumour necrosis factor- $\alpha$ release from macrophages. Br J Pharmacol 2000;129:909-914.

29 Shieh CH, Heinrich A, Serchov T, van CD, Biber K: P2X7-dependent, but differentially regulated release of IL-6, CCL2, and TNF- $\alpha$ in cultured mouse microglia. Glia 2014;62:592607.

30 Weaver CT, Hatton RD, Mangan PR, Harrington LE: IL-17 family cytokines and the expanding diversity of effector $\mathrm{T}$ cell lineages. Annu Rev Immunol 2007;25:821-852.
31 Flierl MA, Rittirsch D, Gao H, Hoesel LM, Nadeau BA, Day DE, et al: Adverse functions of IL-17A in experimental sepsis. FASEB J 2008;22:2198-2205.

32 Atarashi K, Nishimura J, Shima T, Umesaki Y, Yamamoto M, Onoue M, et al: ATP drives lamina propria $\mathrm{T}_{\mathrm{H}} 17$ cell differentiation. Nature 2008;455:808-812.

33 Kusu T, Kayama H, Kinoshita M, Jeon SG, Ueda Y, Goto Y, et al: Ecto-nucleoside triphosphate diphosphohydrolase 7 controls Th17 cell responses through regulation of luminal ATP in the small intestine. J Immunol 2013;190:774-783.

34 Chung CS, Watkins L, Funches A, LomasNeira J, Cioffi WG, Ayala A: Deficiency of $\gamma \delta$ $\mathrm{T}$ lymphocytes contributes to mortality and immunosuppression in sepsis. Am J Physiol Regul Integr Comp Physiol 2006;291:R1338R1343.

35 Steinhauser ML, Hogaboam CM, Lukacs NW, Strieter RM, Kunkel SL: Multiple roles for IL-12 in a model of acute septic peritonitis. J Immunol 1999;162:5437-5443.

36 Moore KW, de Waal MR, Coffman RL, O'Garra A: Interleukin-10 and the interleukin-10 receptor. Annu Rev Immunol 2001;19: 683-765.

37 O'Garra A, Vieira PL, Vieira P, Goldfeld AE: IL-10-producing and naturally occurring CD4+ Tregs: limiting collateral damage. J Clin Invest 2004;114:1372-1378.

-38 Olliver M, Hiew J, Mellroth P, HenriquesNormark B, Bergman P: Human monocytes promote Th1 and Th17 responses to Streptococcus pneumoniae. Infect Immun 2011;79: 4210-4217.

39 Hemmer CJ, Vogt A, Unverricht M, Krause R, Lademann M, Reisinger EC: Malaria and bacterial sepsis: similar mechanisms of endothelial apoptosis and its prevention in vitro. Crit Care Med 2008;36:2562-2568.

40 Hotchkiss RS, Swanson PE, Cobb JP, Jacobson A, Buchman TG, Karl IE: Apoptosis in lymphoid and parenchymal cells during sepsis: findings in normal and T- and B-cell-deficient mice. Crit Care Med 1997;25:12981307.

41 Moulding DA, Walter C, Hart CA, Edwards SW: Effects of staphylococcal enterotoxins on human neutrophil functions and apoptosis. Infect Immun 1999;67:2312-2318.

-42 Goncalves RG, Gabrich L, Rosario A Jr, Takiya CM, Ferreira ML, Chiarini LB, et al: The role of purinergic $\mathrm{P} 2 \mathrm{X} 7$ receptors in the inflammation and fibrosis of unilateral ureteral obstruction in mice. Kidney Int 2006;70: 1599-1606.

43 Stearns-Kurosawa DJ, Osuchowski MF, Valentine C, Kurosawa S, Remick DG: The pathogenesis of sepsis. Annu Rev Pathol 2011; 6:19-48. 